ment. We do not agree. Surely it is better to recognise the importance of obstetric anaesthetic services and improve the services where they are inadequate. Currently the recruitment of doctors into anaesthesia is excellent and the opportunity exists. Unfortunately, medical administrators seeking to save money might misuse the views of Professor Hibbard and his colleagues and block the improvements that are necessary. This is the true importance of the argument.

D J BOWEN

\section{A T LETCHWORTH}

A D NOBLE

Department of Obstetrics and Gynaecology,

Royal Hampshire County Hospital, Wincheste

1 Noble, A D, et al, Journal of Obstetrics and Gynae-

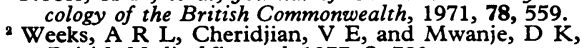
Weeks, A R L, Cheridjian, V E, and M
British Medical fournal, 1977, 2, 730.

3 Willocks, J, and Moir, D D, fournal of Obstetrics and 225 .

\section{Airport hygiene}

SIR,-Dr T D V Swinscow's letter (20 October, p 999) raises the whole issue of standards of cleanliness and hygiene in public facilities. Among the most striking things to confront the British traveller to Canada are the almost complete absence of litter (for example, in the Toronto subway system) and the uniformly smart and clean appearance of the people who work in the catering trade. It is a rarity in restaurants not to find clean facilities and adequate soap and paper towels. Such things seem the exception rather than the rule in England. Last time I went into the buffet at Victoria Station for a cup of coffee I felt as if I was in a garbage hole. An improvement in these facilities would do far more for the British tourist trade than many other promotional gimmicks currently employed.

D J HARRIS

University Department of Psychiatry, University Department of
Ottawa, Ontario K1N 7H5, Canada

\section{Treatment of chronic paronychia}

SIR,-I read with interest the comments of Dr K A V Cartwright and others (17 November, p 1294) on your expert's reply to the questions about the treatment of chronic paronychia. Having been a consultant dermatologist for over 40 years, I have seen a great many of these disabled patients, many of whom have undergone heroic and often very painful therapy without avail. Surely the underlying basic cause is damage to the cuticle, which normally effectively seals the potential space between the nail and the overlying nailfold. This can be damaged by many things-cold in Raynaud's syndrome, as mentioned in the article; heavy manicure; accidental trauma; over-exposure to alkaline cleansing agents; constant immersion in syrup (as in the fruit canning industry); and even the application of adhesive plaster over a period of days, as shown years ago by $\mathrm{Dr}$ Howard Whittle; and so on. Cure therefore depends on restoring the normal cuticle. Immersion in water prevents this, but it is quite unrealistic to expect a busy woman to avoid all contact with water for the six to eight weeks required for the cuticle to regrow. I have treated this condition very successfully by explaining the problem to the patient and then prescribing a nystatin-containing ointment with the instructions that this should be worked into the affected nailfold using the thumb of the other hand every time she is going to get her hands wet. This may be 20-30 times daily, but the time taken to do it is negligible. This is continued until the cuticle has regrown-a period of about six weeks, but longer in patients with the "chilblain" type of circulation.

The cure depends, in my opinion, very largely on having a water barrier in the nailfold rather than on the fungicidal or antibacterial action of the application. Years ago my sceptical friends would not believe that such a simple remedy worked, so before I held my next national dermatological meeting in Oxford I wrote to six patients chosen at random from our diagnostic index, and let my colleagues see the grateful patients-who all turned up cured by this simple method.

H R VICKERS

Hammersmith Hospital London W12 0HS

\section{Subsidy of social functions by drug companies}

SIR,-At a recent meeting of trainees from the Exeter GP vocational training scheme it was agreed by a majority decision that subsidies from pharmaceutical companies would not be sought in future for trainee-organised social functions.

General practitioners are probably the most vulnerable group of the medical profession so far as the promotional efforts of the drug companies are concerned. In many cases they do not have the facilities for critical discussions with colleagues of the information put forward by representatives and advertisements. Patterns of prescribing change following visits by drug company representatives, and were this form of promotion not cost effective in terms of increased use of the product in question the companies would have to stop investing large sums of money by advertising in this way.

In view of the above points I feel that it is commendable that the move to reject such methods of advertising by drug company representatives should come from a group of GP trainees and that they are leading general practitioners and the medical profession as a whole in this way. This represents an important advance in awareness of the potential problems inherent in accepting pharmaceutical companies' subsidisation of social functions and, to my knowledge, this is the first time that a group of doctors have made such a decision.

Royal Devon and Exeter Hospital (Wonford)

D Hilton Exeter EX2 5DW

\section{"A Touch of Sensitivity"}

SIR,-The Horizon programme $A$ Touch of Sensitivity not only confirmed our knowledge of the necessity for intimate contact between mother and baby but-a point not mentioned by your reviewer (17 November, p 287)-it also drew our attention to the importance of non-genital touching for a happy marriage.

The marriage counsellor interviewed showed how a couple could reawaken their mutual love by such simple acts as stroking the partner's arm, provided that a point was reached where the one doing the stroking desired not so much his own pleasure as to give happiness to the other. This brings to mind the constant teaching of Dr John Billings and his co-workers in Melbournethat love can be fostered between a couple even when genital contact is temporarily ruled out. Since 1964 they have developed and extensively researched the form of natural family planning known as the ovulation method. This relies entirely on the presence or absence at the vulva of cervical mucus, with observations of the changing or unchanging characteristics of the mucus. By these "observations" (some of its users are blind) the days of probable fertility can be discerned. One of the most important "rules" of the method is that on fertile days there must be no genital contact whatsoever between the couple if pregnancy is to be avoided (the use of barrier methods alters the secretions at the vulva). During the past year the World Health Organisation has conducted a survey of the method in five countries.

An Atlas of the Ovulation Method and other literature, including reprints of articles published in professional journals, can be obtained from the Ovulation Method Research and Reference Centre of Australia, 86 Wellington Parade, East Melbourne, Victoria 3002.

\section{Christine M Fitzgerald}

Stockport SK6 6AH

\section{Bronchodilator effect of sodium cromoglycate}

SIR,-I read with interest the paper by Drs J T N Chung and R S Jones (27 October, $p$ 1033) on the bronchodilator effect of sodium cromoglycate (SCG) in children. Since this phenomenon has not been reported in adults they raise the possibility that children and adults have different physiological responses to SCG.

As an atopic asthmatic I can report a good subjective and objective (as measured by peak expiratory flow rate) bronchodilator response to SCG in doses of $20 \mathrm{mg}$ taken via the "Spinhaler." I thought that I was unique in this way until I recently treated a 19-yearold atopic asthmatic girl who reported that she used her SCG only when she felt wheezy -and was relieved of her wheeze in a short time.

Bingley, W Yorks BD16 4AB

Philip Helliwel

\section{Rubella vaccination and unnecessary abortions}

SIR,-We question the recent advice given by the DHSS that women who have been vaccinated with a live attenuated rubella vaccine within three months of a pregnancy should be considered to have put the fetus at risk of congential rubella. This ruling undoubtedly leads to a number of unnecessary abortions at a time when indications for abortion are becoming increasingly strict.

We understand that the ruling arises from an American report that live rubella virus was recovered from a fetus when the mother had been vaccinated seven weeks before conception. There is now, however, some evidence to show that the vaccines used in America are not teratogenic. We would like to suggest that the 